\title{
Visual search in multicharacter arrays with and without gaps
}

\author{
JUDITH RICH HARRIS, MARILYN L. SHAW, and MARSHA BATES \\ Rutgers-The State University, New Brunswick, New Jersey 08903
}

\begin{abstract}
Subjects searched through briefly presented arrays of letters in a controlled order, indicating quickly which of two possible targets had occurred. Some arrays contained gaps-three missing letters. Reaction time (RT) and accuracy were both improved by a gap after the target; improvement was less when the gap preceded the target. To account for these results, a new model is proposed, one which calls for overlapping processing of successive array items. This is not a "hybrid" model, but a third alternative between the two extremes of serial (zero overlap) and parallel (complete overlap). Quantified, the overlapping model generates U-shaped serial-position curves and produces RT predictions in good accord with our data from arrays with and without gaps. The predicted functions for RT vs. array size are concave upward; however, for arrays of five or less they are virtually linear and not very different in slope for positive and negative trials. Although this model is primarily designed for RT, with some additional assumptions it can be extended to accuracy results.
\end{abstract}

When an array of alphanumeric characters is flashed briefly, a visual representation of the array remains available to human subjects for a short time afterwards (Sperling, 1960). During this time, it is possible to "read" the characters, almost as if they were still present. Subjects can, for example, search the array for some particular letter or letters.

Sternberg (Note 1) has proposed a model for this kind of visual search, based on an experiment that has become one of the standard paradigms for information-processing research. In this experiment, a horizontal string of characters was presented briefly to the subject, who had previously memorized a list of letters or numbers called the "memory set." The task was to decide as quickly and accurately as possible whether any character from the memory set was present in the display, and to signal "yes" or "no" accordingly. Since the error rate was kept low, the measure of interest was reaction time (RT). Sternberg found that mean RT (RT) increased linearly with the size of the memory set; the slope of this function increased linearly with the number of items in the display. These data were consistent with Sternberg's model, which postulates serial search that is exhaustive in the memory set but self-

This research was supported in part by a grant to the second author from the Rutgers University Research Council. Requests for reprints should be addressed to Judith Rich Harris, 29 Crane Circle, New Providence, New Jersey 07974. The authors wish to extend their warmest thanks to Rolf Levenbach, who gave freely of his leisure time in order to program the model presented here; to George Levenbach, who permitted us to use his personal computer (a Polymorphics $\mathbf{8 8}$ microcomputer system); and to $\mathbf{R}$. Duncan Luce and David A. Rosenbaum, for their many valuable comments on an earlier version of this paper. terminating in the display: The subject processes each character in the display in turn, running rapidly through the list of memory-set items each time, until either a match is found ("yes") or the display is exhausted ("no").

Given the assumption that items in an array are processed one at a time until a solution is reached, on a "yes" trial RT should vary with the ordinal position of the target: targets later in the processing order should produce longer RTs. However, this cannot be demonstrated unless there is some consistency in the order of processing used by the subjects. Since the function relating $\overline{\mathrm{RT}}$ to the position of the target in the display was essentially flat in Sternberg's data, he concluded that subjects varied their processing orders, using a mixture of left to right and right to left.

P. Shaw (1969) developed techniques for bringing under experimental control the order in which subjects process display items. When the desired processing order was left to right, he positioned the display in the right visual field, instead of centering it as Sternberg had done. Thus, the leftmost letter was closest to the fixation point. Subjects were instructed to "process or 'read' the displays from left to right" and, in addition to responding to the target, were required to report the leftmost letter with almost perfect accuracy. A target was present on every trial; subjects reported which of two possible targets had appeared. The dependent variable was the proportion of correct target identifications. P. Shaw found that this proportion declined with the ordinal position of the target in the processing sequence, a relationship known as the serial-position effect. He attributed this decline to the fact that the visual 
representation (or trace) of the characters late in the processing order had undergone more decay by the time they were processed.

Removing one or more adjacent characters from a display, leaving a gap, provided a further test of the self-terminating serial model. P. Shaw reasoned that omitting the characters preceding the target in the processing order should improve accuracy: the processing time that these characters would have required is saved, so the target can be processed sooner and its trace has less time to decay. On the other hand, if processing ceases when the target is found, then omitting the characters following the target should make no difference. The results of $P$. Shaw's experiments were just the opposite of those predictions: a gap preceding the target in the instructed processing order had little or no effect on accuracy, whereas a gap following the target produced a notable improvement! This was true whether the instructed processing order was from left to right or from right to left.

Although a self-terminating serial model cannot account for this increase in accuracy produced by a gap after the target, $P$. Shaw's experiments had little impact on theorists primarily interested in $\overline{\mathrm{RT}}$. It cannot simply be assumed that gaps will have an effect on $\overline{\mathrm{RT}}$ that corresponds to the effect on accuracy, despite the close agreement usually found between these two measures of performance. The necessary experimental test of the effects of gaps on $\overline{\mathrm{RT}}$ has not yet been reported. To provide these data is a major purpose of the present paper.

The paradigm of interest here is visual search. In a search paradigm, subjects look for a single target regardless of the number of items in the array. Their response is either a judgment of the presence or $a b-$ sence of the target (as in Sternberg's experiment) or a two-alternative choice of its identity (as in $P$. Shaw's). The other characters in the array are "background" or "distractors"; they need only enough processing to eliminate them from further consideration. A number of other studies of gaps have appeared (Estes \& Wolford, 1971; Townsend, Taylor, \& Brown, 1971; Wolford \& Hollingsworth, 1974), but these subsequent studies have all used the whole-report procedure. In this paradigm, subjects attempt to name every character in the array. Thus, varying the number of items in the array changes not only the amount of visual processing required, but also the number of items that must be remembered and reported.

The study of the effects of gaps is of interest both in its own right and in its relevance to the various theories of information processing. Any model dealing with visual search in multicharacter arrays should be able to account for the consequences of removing some of these characters. A brief review of the major types of current models will indicate the difficulties presented to these models by gap effects, and by other closely related effects of processing order, target position, and the number of items in the array.

\section{Serial Models}

Even without RT data on the effects of gaps, problems exist for the self-terminating serial model. The most serious one concerns array size and the difference between negative trials (those on which no target is present) and positive trials. On negative trials, the subject must process every item in the array before he can respond correctly. On positive trials, with the target located randomly within the array, on the average only half of the items must be processed. Thus, the function relating $\overline{\mathrm{RT}}$ to array size should go up twice as fast for negative trials as for positive trials. Although Sternberg (Note 1) obtained this result, in later studies it has been more common to find that positive and negative slopes are virtually the same (Atkinson, Holmgren, \& Juola, 1969; Townsend \& Roos, 1973).

To solve this problem, a model was proposed postulating exhaustive processing of display items. In exhaustive serial search, no decision is made until all display items have been processed. Positive and negative slopes should therefore be equal. The fact that the intercept is generally higher for negative decisions can simply be attributed to the greater difficulty involved in making such decisions.

A major embarrassment for the exhaustive search model is the existence of the serial-position effect. Since every item is processed on every trial, the location of the target should make no difference. Yet, when processing order is controlled, it is clear that responses are quicker to targets in early positions than in later ones (M. L. Shaw, 1977; Townsend \& Roos, 1973).

If the asymmetry of the gap effect found with accuracy holds true for $\overline{\mathrm{RT}}$ as well, the exhaustive serial model is no better able to account for this phenomenon than is the self-terminating model. Although omitting some characters from an array should certainly improve performance, with exhaustive search it should make no difference where in the array the gap occurs.

P. Shaw (1969) presented a third type of serial model as an explanation of his results. This scanning model, which predicts accuracy rather than RT, has two components. The first, a character finder, scans the array in the instructed order, moving at a constant rate independent of the kind and number of objects in the visual field. When it locates a character, that character is sent immediately to the second component: a reader that can handle only one character at a time. Whenever the finder forwards a new 
character, the reader stops processing the previous one. Thus, when a gap follows a character, the reader has extra time to process that character, but when a gap precedes it, no time is gained. It is assumed that longer processing time results in more accurate identification of the character.

Unfortunately for this model, other studies did not support P. Shaw's finding that a gap before a character produces no significant improvement in responses to that character. Later experiments, performed with the whole-report procedure, found that a gap on either side of a character aided performance (Estes \& Wolford, 1971; Townsend et al., 1971; Wolford \& Hollingsworth, 1974). However, the asymmetry remained: gaps on the far side were more efficacious than gaps on the near side.

\section{Parallel Models}

The statement that a gap after a character improves performance more than a gap before it can be put in a different way: items on one side of a character interfere with it more than do items on the other. P. Shaw (1969) considered the possibility that gaps reduced lateral interference from neighboring characters. To test this, he ran an experiment in which the missing letters were replaced by a solid black rectangle or bar instead of an empty space. He reasoned that, although a black bar does not require processing as a character, it should produce more interference or masking than a blank space. The pattern of results he obtained with the bars appeared to be equivalent to that obtained with spaces; however, the fact that these stimuli did not occur in the same experiment made precise comparisons difficult. P. Shaw concluded that a simple masking explanation did not account for his results. If these data are reliable, they indicate that contour and contrast alone are not adequate to produce the sort of interference that is presumably eliminated by gaps.

Theories involving more subtle forms of mutual interference, however, are still tenable. A reasonable way of explaining how the presence of a character can affect the response to its neighbor is to assume that both are being processed in parallel (Estes, 1972; Estes, Allmeyer, \& Reder, 1976; Gardner, 1973; Rumelhart, 1970). Since parallel models assume that all characters are processed simultaneously (at least during the first stage), there is no "processing order." Serial-position and gap effects are generally attributed to: (1) the distance from the fixation point, or retinal locus, of an item; (2) interrelationships among items in the array, chiefly interference or competition from adjacent characters; and/or (3) the way that attention or processing capacity is distributed.

Estes and Wolford (1971) tested the hypothesis that the asymmetrical effects of gaps are due to their relative distance from the fixation point. In P. Shaw's (1969) experiment, processing order was always in the direction away from the fixation point, so that the effects of processing order were confounded with those of distance from the fovea. Estes and Wolford separated these two variables by adding conditions in which "readout order" was toward the fixation point. They found that both factors yielded significant effects: a gap on the peripheral side of a character aided performance more than a gap on the central side; a gap after a character in the "readout order" aided performance more than a gap before it. However, processing order was of greater importance than retinal locus. Of course, the relative weight of these two factors will depend on the size of the retinal angle subtended by the display: the wider the angle, the more important this factor becomes. Retinal angle varies greatly from one study to another, ranging from the $1.5^{\circ}$ used by Estes and Wolford to the $10.6^{\circ}$ used by Estes et al. (1976).

The serial-position effect is also determined more by processing order than by retinal locus. This was shown by Estes and Wolford for accuracy and by M. L. Shaw (1977) for $\overline{R T}$. Using four target positions in a 10 -item display subtending $2^{\circ}, M$. L. Shaw found that only $17 \%$ of the variance in her data was attributable to the effect of retinal locus. Processing order accounted for $50 \%$ to $60 \%$. Estes and Wolford gave whole-report data for nine-item displays, showing that the serial-position effect is not a monotonically declining function: it is somewhat U-shaped. But, whether processing order was toward the fixation point or away from it, performance for the first item processed was always considerably better than for the last.

The superior response to the items at the two ends of an array has been noted many times; more often than not, these "end effects" are regarded as a nuisance. Many experimenters (e.g., Atkinson et al., 1969; Estes et al., 1976; Holmgren, 1974; Krumhansl \& Thomas, 1976) even attempt to avoid these effects by adding "irrelevant" characters on either end of the array. Clearly, there is a close logical relationship between being next to a gap and being at the end of the array-i.e., next to an essentially infinite gap. An array with a gap really has four ends instead of two. Unfortunately, this does not account for the asymmetry of the gap effects. The most beneficial position for a gap is after a character, which makes that character, in effect, the last item in a string. It is the first item in an array, however, that possesses the greatest advantage.

If retinal locus alone is inadequate to account for the effects of gaps and the serial-position curve, what about retinal locus plus the selective allocation of attention or processing capacity? Since display items farther from the fixation point are harder to 
see, Krumhansl and Thomas (1976) postulate that extra attention is assigned to these locations. Then a gap on the peripheral side of a character would free more attention than a gap on the central side. We must assume that this attention can be quickly reassigned to the neighboring locations upon the appearance of a gap.

Another viewpoint would reverse the priorities. M. L. Shaw (1978; M. L. Shaw \& P. Shaw, 1977) presented an optimization model for the allocation of limited capacity in visual search, in which greater capacity is allocated to the more "visible" items (Koopman, 1957). The prediction for the present situation is that more attention should be assigned to items near the fixation point. When a gap occurs, the "leftover" attention must be reassigned, not symmetrically, but with more going to the items on the foveal side. This view is given credibility by the fact that many of M. L. Shaw's (1978) subjects allocated their attention in a way that closely approximated the optimal allocation derived from her model.

Both of these attention models can account for the asymmetrical effects of gaps with respect to retinal locus. With an additional assumption, that attention is also allocated according to the instructed processing order, processing order effects can be explained as well. The question that remains is whether processing capacity or attention can be redistributed quickly enough, when a gap appears. Eriksen and Hoffman (1972) found that 100 to $200 \mathrm{msec}$ are required for a cue to redirect attention to a particular part of a display. Holmgren (1974) performed a visual search experiment in which a marker (a black vertical line) sometimes appeared over the target. If the subjects did not know on which trials markers would appear, the marker had no effect on $\overline{\mathrm{RT}}$. Even when they did know, the marker did not eliminate processing of other display items-just speeded it up slightly. Kinchla (1977) has also demonstrated the inability of subjects to redistribute attention rapidly on the basis of form information provided by the display itself. These data all cast serious doubt on the assumption that when a gap appears subjects can quickly reassign their attention.

\section{The Nature of the Experiments}

The two experiments reported here are an attempt to answer some of the questions that emerged in the above survey. Experiment 1 was designed to test the effects of gaps on $\overline{\mathrm{RT}}$, and to confirm or disconfirm $P$. Shaw's (1969) report of the equivalence of spaces and bars. Since, in this experiment, a gap (three missing characters) was always immediately adjacent to a target, it could possibly be considered as a kind of marker, drawing attention to the target. Although Holmgren's (1974) findings make this interpretation tenuous, a condition was included that permits us to make a direct comparison of the effects of gaps and those of markers: on some trials, not announced in advance, a vertical black bar appeared directly over the target. No gap was present on those trials.

In reaction-time experiments, error rates are usually kept quite low; only correct responses are used to calculate $\overline{\mathrm{RT}} \mathrm{s}$. Pachella (1974) has pointed out the hazards involved in this technique: because of the speed-accuracy tradeoff, when the probability of a correct response is high a relatively large increase in speed can be bought for a relatively small loss of accuracy. For this reason, Pachella argues, RT data can be misleading if small differences in percentage correct are ignored. Both RT and accuracy were measured in Experiment 1. The purpose of Experiment 2 was to examine, under comparable conditions, the pattern of accuracy results obtained when the probability of a correct response is allowed to vary over a wider range. In addition, the second experiment constitutes a test of the reliability of $P$. Shaw's findings, which have never been replicated within the original context of visual search.

\section{METHOD}

\section{Experiment 1}

Subjects. Four Rutgers University undergraduates served as paid subjects. Their vision was normal or was corrected to $20 / 20$.

Stimuli. As shown in Table 1, there were three types of displays: displays with gaps, displays with markers, and control displays. Control displays consisted of horizontal strings of 10 capital letters, subtending $1^{\circ} 48^{\prime}$ of visual angle. Every display contained one target, either an $S$ or an $R$, that appeared only in position 3, 5 , or 7. Position 1 always contained a "verification letter," either a $\mathrm{J}$ or a $\mathrm{T}$. The remaining letters in the display were background items: four Ns and four Xs, randomly arranged.

Displays with gaps were generated by removing three consecutive background letters from control displays with the target in position 5 and 7 . Letters 2,3 , and 4 or 6,7 , and 8 were removed for targets in position 5 ; letters 4,5 , and 6 or 8,9 , and 10 were removed for position 7 . Two sets of these displays were used; in half of them, the gap left by the missing letters was left blank, in the other half, it was filled with a black rectangle or bar.

Table 1

Sample Displays

\begin{tabular}{lcccccccccccc}
\hline Display Condition & P* & \multicolumn{1}{c}{} \\
\hline Control & 3 & J & N & S & N & X & X & N & X & N & N \\
(No Gap) & 5 & T & N & N & X & R & X & N & X & X & N \\
& 7 & J & X & N & X & N & N & S & X & N & X \\
Gap Before Target & 5 & J & & & & S & N & N & X & X & N \\
(Space) & 7 & T & X & N & & & & R & N & X & X \\
Gap After Target & 5 & T & N & X & X & R & & & & N & X \\
(Space) & 7 & J & X & X & N & N & X & S & & & \\
Marker & & & & & & . & & & & & \\
& 5 & T & X & N & N & S & X & X & N & X & N \\
& 7 & T & N & X & X & N & N & R & N & X & X \\
\hline
\end{tabular}

$* P=$ target position. 
Marker displays contained no gaps. They were constructed by placing a vertical bar over targets in positions 5 and 7.

The letters were typed in black, on white cards, with an IBM Orator Typeball. Each letter was $5.0^{\prime}$ wide and $10.8^{\prime}$ high in visual angle. The space between letters was $6.5^{\prime}$. Bars and markers were solid black rectangles the same height as a letter. Bars were 28.0' wide; the space between a bar and the nearest letter was the same as the space between adjacent letters. Markers were the same width as a letter; the vertical angle between a marker and a letter was $4.0^{\prime}$.

Sixteen different displays were constructed for each of the three target positions in the control condition. For each of the two target positions in the experimental conditions, there were eight displays for each of five conditions (spaces before and after the target, bars before and after the target, and markers over the target). These 128 displays were used twice in a session, in random order.

Each display was positioned in the right visual field so that the leftmost letter appeared in the center, immediately below the location of the fixation point. The fixation field was a white card with a black dot in its center; this was visible throughout the session except during presentation of a display.

Apparatus. A Scientific Prototype Model GB three-field manual tachistoscope presented the displays. The luminance of the stimulus and fixation fields was $10 \mathrm{fL}\left(34.3 \mathrm{~cd} / \mathrm{m}^{2}\right)$, as measured by a Salford Electrical Instruments photometer. The luminance level was checked between blocks of trials using a photopically corrected photocell mounted in the hood of the tachistoscope and connected to a battery-operated meter.

Response times were measured with a Psyonic crystal-based timer. The subjects activated display presentation and the timer by depressing a foot pedal, and stopped the timer by pressing a lever with their right hands.

Procedure. The instructed "reading"' order was always from left to right, from the letter nearest the fixation point to the letter farthest away. To insure that subjects actually began at position 1 , they were required on every trial to report the letter in the first position, the "verification letter." Control displays with targets in position 3 were included partly to discourage subjects from skipping to position 5 .

The instructions to the subject were as follows: "(a) Each display has either an $S$ or an $R$ in it, but not both. This target letter may appear in either the third, fifth, or seventh display position from the left. Whenever a marker (a vertical bar) appears above the display, the target is immediately below it. (b) To view a display, fixate on the dot in the center of the field and then press the foot pedal. (c) "Read" the displays from left to right. (d) Press the lever to the right if the target letter is $R$, to the left if it is S. Respond as quickly as possible, but avoid making errors. (e) Immediately after making your response, report the verification letter to the experimenter. The verification letter is in the first, or leftmost, position; it is either a $J$ or a $T$. (f) It is important to fixate on the dot and to be nearly $100 \%$ accurate in reporting the verification letter."
Each subject participated in two practice and four experimental sessions. Feedback was provided only during practice sessions. The 256 trials per session were given in blocks of 64 , with a short rest between blocks. Prior to each experimental session, the subjects were dark-adapted for $10 \mathrm{~min}$ and then given 10 practice trials.

During practice sessions, display duration was gradually reduced from 250 to $100 \mathrm{msec}$; it remained at $100 \mathrm{msec}$ throughout the four experimental sessions.

\section{Experiment 2}

Subjects. Three Rutgers University undergraduates, none of whom had served in Experiment 1, were paid for their participation. Their vision was normal or was corrected to $20 / 20$.

Stimuli. All the stimuli used in Experiment 1 were also used in this experiment, with the exception of marker displays and displays with spaces. All of the gaps in Experiment 2 contained bars. In order to prevent subjects from using the location of the bar to "home in" on the target, some displays were added that contained bars not adjacent to the target. In these displays, the target was in position 3; the bars were in three different locations; positions 5,6 , and $7 ; 6,7$, and $8 ;$ or 7,8 , and 9 .

Apparatus. The apparatus was the same as in Experiment 1, except that no lever or timer was used, because only accuracy was measured. Subjects' responses were made verbally and recorded by the experimenter. The luminance of the stimulus and fixation fields was $5 \mathrm{fL}\left(17.1 \mathrm{~cd} / \mathrm{m}^{2}\right)$.

Procedure. The instructions were the same as in Experiment 1, except that no reference was made to a marker, and instruction d was changed to: "Immediately after viewing the display, report the target letter."

Each subject participated in three practice and six experimental sessions. Feedback was provided only during practice. Before each experimental session, the subjects had $6 \mathrm{~min}$ of dark adaptation and 10 practice trials. An experimental session consisted of 256 trials, in which verification letter, target letter, target position, and display condition (control, bar before the target, bar after the target, and nonadjacent bar) were counterbalanced.

During practice sessions, display duration was gradually reduced until approximately $75 \%$ of the subject's responses to target position 5 control displays were correct. This duration was maintained during the six experimental trials. The durations used were 39, 35, and $37 \mathrm{msec}$, for Subjects 1, 2, and 3, respectively.

\section{RESULTS}

The $\overline{\mathrm{RT}}$ data from Experiment 1 are shown in Table 2 and in Figure 1a. In calculating $\overline{\mathrm{RT}} \mathrm{s}$, only correct responses were used. The proportions correct in this experiment, given in the center column of Table 3, varied from .83 to .97 for the various conditions; the overall mean was .92. The subjects were

Table 2

Reaction Times for Correct Responses, Experiment 1

\begin{tabular}{|c|c|c|c|c|c|c|c|c|c|c|c|c|}
\hline \multirow[b]{3}{*}{ Subject } & \multicolumn{4}{|c|}{$\begin{array}{c}\text { (a) Gaps Before Target: } \\
\text { Bars vs. Spaces }\end{array}$} & \multicolumn{4}{|c|}{$\begin{array}{l}\text { (b) Gaps After Target: } \\
\text { Bars vs. Spaces }\end{array}$} & \multicolumn{4}{|c|}{ (c) Control vs. Marker } \\
\hline & \multicolumn{2}{|c|}{ Target Position 5} & \multicolumn{2}{|c|}{ Target Position 7} & \multicolumn{2}{|c|}{ Target Position 5} & \multicolumn{2}{|c|}{ Target Position 7} & \multicolumn{2}{|c|}{ Target Position 5} & \multicolumn{2}{|c|}{ Target Position 7} \\
\hline & Bar & Space & Bar & Space & Bar & Space & Bar & Space & Control & Marker & Control & Marker \\
\hline $\begin{array}{l}1 \\
2 \\
3 \\
4\end{array}$ & $\begin{array}{l}557 \\
540 \\
598 \\
440\end{array}$ & $\begin{array}{l}570 \\
522 \\
606 \\
445\end{array}$ & $\begin{array}{l}616 \\
592 \\
701 \\
565\end{array}$ & $\begin{array}{l}615 \\
582 \\
692 \\
571\end{array}$ & $\begin{array}{l}555 \\
533 \\
618 \\
452\end{array}$ & $\begin{array}{l}571 \\
523 \\
620 \\
457\end{array}$ & $\begin{array}{l}570 \\
548 \\
638 \\
458\end{array}$ & $\begin{array}{l}600 \\
538 \\
626 \\
448\end{array}$ & $\begin{array}{l}570 \\
550 \\
662 \\
466\end{array}$ & $\begin{array}{l}600 \\
554 \\
657 \\
470\end{array}$ & $\begin{array}{l}650 \\
635 \\
766 \\
520\end{array}$ & $\begin{array}{l}640 \\
580 \\
784 \\
493\end{array}$ \\
\hline Mean & 534 & 536 & 618 & 615 & 540 & 543 & 554 & 553 & 562 & 570 & 643 & 624 \\
\hline
\end{tabular}




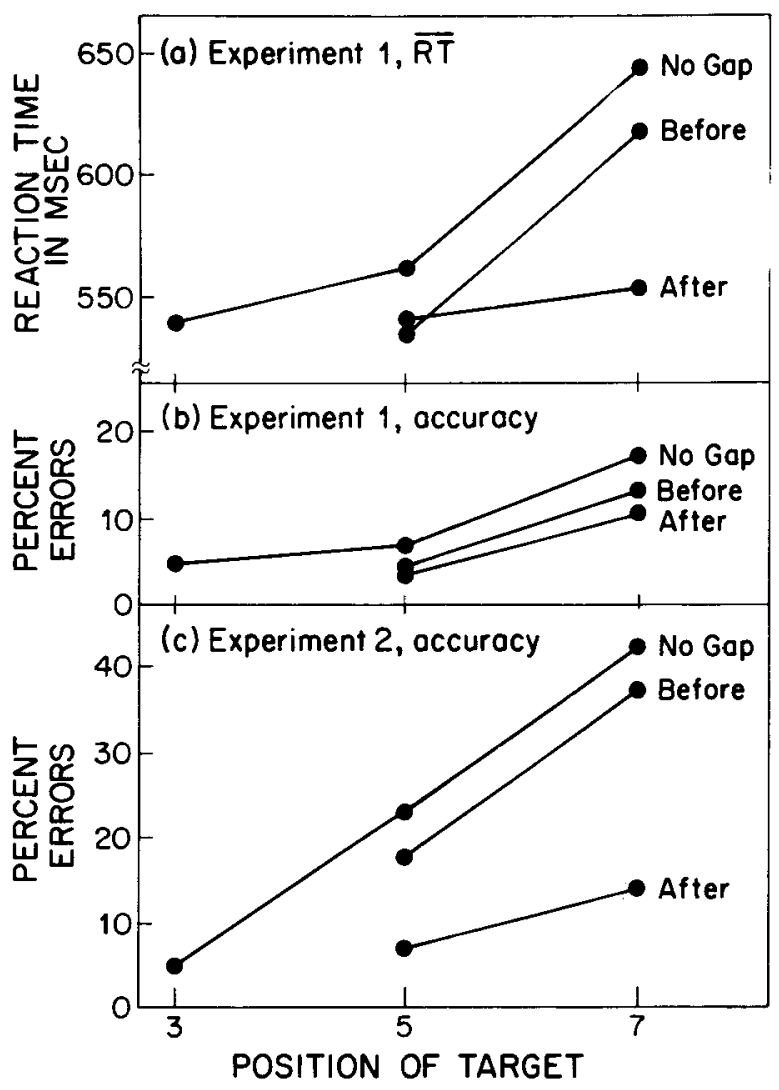

Figure 1. Mean reaction time and percentage of errors as a function of the position of the target in the instructed processing order and the gap condition: BEFORE, a gap before the target; AFTER, a gap after the target; and NO GAP, control.

at least $98 \%$ correct in reporting the verification letter.

$\overline{\mathrm{RT}}$ was not affected by the presence or absence of a black bar in the gap left by the three missing letters. Spaces and bars yielded indistinguishable results, whether they appeared before the target (Table 2a) or after the target (Table $2 b$ ). These results extend to $\overline{\mathrm{RT}}$ the equivalence of spaces and bars that P. Shaw (1969) found with accuracy measures. Overall $\overline{\mathrm{RT}}$ in Experiment 1 was $561 \mathrm{msec}$ for displays containing spaces, $562 \mathrm{msec}$ for displays containing bars. This close agreement was supported by the overall proportions correct: .93 for spaces, .92 for bars. Since there was no detectable difference in performance for spaces and bars, the data from these two conditions were combined. We use the term "gap" to refer to both of these conditions; it implies only that characters have been omitted from a display.

Figure 1a shows $\overline{\mathrm{RT}} \mathrm{s}$ from Experiment 1 for displays containing gaps before the target, gaps after the target, or no gaps (control); the target letter appeared in position 3,5 , or 7 . Although overall performance for the four subjects ranged from an $\overline{\mathrm{RT}}$ of $478 \mathrm{msec}$ for Subject 4 to $660 \mathrm{msec}$ for Subject 3, within each subject relative $\overline{\mathrm{RT}} \mathrm{s}$ for the different conditions closely resembled those shown in Figure 1a. Standard errors of the means for individual subjects ranged from 5 to $13 \mathrm{msec}$.

As seen in Figure 1a, gaps have a sizable effect on performance: in general, $\overline{\mathrm{RT}} \mathrm{s}$ were less for displays with gaps than for displays without gaps. In addition, the effect of gaps after the target was significantly greater than that of gaps before the target. The RTs of correct responses for positions 5 and 7 were analyzed with the general linear models program of the Statistical Analysis System. The results of this linear regression were: position of target, $\mathrm{F}(1,3086)=100.6, \mathrm{p}<.0001$; display condition (spaces and bars before and after the target, and control), $F(5,3086)=9.4, p<.0001$; and Target Position by Display Condition, $F(5,3086)=5.4$, $\mathrm{p}<.001$.

The effects of gaps did not appear to be due to an ability to attract attention, as these effects were quite different from those of markers. Table 2c shows $\overline{\mathrm{RT}} \mathrm{s}$ of individual subjects for the control (no-gap) condition and the marker condition; these means did not differ significantly. Overall, $\overline{R T}$ was $597 \mathrm{msec}$ for the marker condition and $602 \mathrm{msec}$ for the control condition. With regard to accuracy, the marker did make a noticeable improvement: .94 correct for the marker condition vs. .88 for the control, significant by a two-tailed $\mathrm{z}$ test at the .05 level.

In Figure 1b, the accuracy results from Experiment 1 have been plotted as percentage of error, so that they are directly comparable with the $\overline{\mathrm{RT}}$ results from this experiment shown in Figure 1a; in both graphs, performance gets worse as distance from the abscissa goes up. A comparison of Figures 1a and $1 \mathrm{~b}$ indicates that relative accuracy performance on these seven conditions varied in close correspondence with relative $\overline{\mathrm{RT}}$ performance.

Table 3

Mean Proportions Correct for Experiments 1 and 2

\begin{tabular}{lcc}
\hline Display Condition & Experiment 1 & Experiment 2 \\
\hline Verification Letter & .99 & .99 \\
Target Position 3 & & \\
$\quad$ Control & .95 & .95 \\
$\quad$ Nonadjacent Gap & & .94 \\
Target Position 5 & & \\
$\quad$ Control & .93 & .77 \\
Marker & .94 & \\
Bar Before Target & .96 & .82 \\
Space Before Target & .95 & \\
$\quad$ Bar After Target & .96 & .93 \\
$\quad$ Space After Target & .97 & \\
Target Position 7 & & \\
$\quad$ Control & .83 & .58 \\
Marker & .93 & .63 \\
Bar Before Target & .85 & .86 \\
Space Before Target & .89 & \\
$\quad$ Bar After Target & .89 & .90 \\
$\quad$ Space After Target & .90 & \\
\hline
\end{tabular}


Figure $1 \mathrm{c}$ shows the accuracy results for these same conditions from Experiment 2, also plotted as percentage of incorrect responses. Each of these percentages is based on 100 data points. Intersubject variability in this experiment was very low, since exposure time was adjusted to equalize performance: overall accuracy was $79 \%$ for each subject. Mean proportions correct for all the conditions of Experiment 2 are given in the right column of Table 3.

An analysis of variance was done on the accuracy results from Experiment 2, for target positions 5 and 7. Significant effects were found for display condition $[F(2,1782)=640.9, p<.001]$ and for target position $[F(1,1782)=106.6, p<.001]$. No interaction proved significant.

The procedure of Experiment 2 is similar to that used by P. Shaw (1969). The results of our experiment replicate those of $P$. Shaw in all important ways but one: we found that a gap before the target did improve performance significantly, as compared with control $(\mathrm{p}<.05$, two-tailed $\mathrm{z}$ test $){ }^{1}$

The main results of our experiments, shown in the three graphs of Figure 1, indicate that target position and gaps have certain general effects on performance, whether performance is measured by $\overline{\mathrm{RT}}$ or by error rate, and whether error rate varies within wide limits or narrow. We can summarize these effects as follows: (1) Performance declines as the position of the target in the instructed processing order goes up. (2) For a given target position, performance is best with a gap after the target, intermediate with a gap before the target, and worst for no gap at all.

\section{DISCUSSION}

Neither serial nor parallel models can fully account for the effects of gaps on visual search performance. Exhaustive and self-terminating serial models are equally unable to explain why a gap after a target improves performance more than a gap before it. Parallel models cannot easily explain why this phenomenon is affected by processing order.

Many of the complications and contradictions in this field may be due to the persistent dichotomy between parallel and serial models. One need not start out with a choice between two mutually exclusive assumptions: that display items are processed either one at a time or all at once. As Taylor (1976) has pointed out, there is an infinite set of possibilities between these two extremes. For example, processing of individual items can overlap in time, and the amount of such overlap can range from zero (i.e., serial) to complete (i.e., parallel). Note that a model of this type is clearly distinct from a mixed model, the kind that Townsend (1974) has labeled "hybrid."

That processing of individual array items may overlap has been proposed. Sternberg and Scarborough
(1971) reported the results of a visual search experiment in which digits were presented sequentially, one at a time, in the same location. The subject was to respond as quickly as possible whenever a target appeared. By measuring RT and varying the size of the memory set, they showed that, although processing of individual items appeared to be serial, processing of one digit began before processing of the preceding one was completed. Sternberg and Scarborough called this "parallel testing." They suggest that something similar may occur in simultaneously presented arrays, and can account for the rapid rates of search attained (using printed materials) by the subjects of Neisser, Novick, and Lazar (1963).

What is needed, in order to process a simultaneously presented array in an overlapping fashion, is some sort of scanning mechanism [such as P. Shaw's (1969) "character finder"] that would convert a spatially ordered set of characters into temporally ordered array. There is ample evidence for such a mechanism; Krueger (1976) summarized some of these data. Sperling (1963) presented other evidence for scanning of multicharacter displays: Both his subjects and those of Baxt (1871) were able to report one additional letter from a display for each increase of roughly $10 \mathrm{msec}$ in the effective (premask) duration of the visual stimulus. Sperling noted (p. 25) that "under a variety of conditions, random letters of good contrast are scanned at the same rate; typically about one letter per $10 \mathrm{msec}$."

A scanning speed in the neighborhood of $10 \mathrm{msec} /$ character shows up in other contexts as well. Sperling, Budiansky, Spivak, and Johnson (1971) presented a series of sequentially flashed multiletter arrays to their subjects, whose task was to search for a single digit imbedded in one of the arrays. The two subjects attained "scanning rates" of 8 and $13 \mathrm{msec}$ per character, in the display conditions that maximized performance. Finally, Neisser $(1964$, p. 102) reported that professional readers for newspaperclipping services "scan newspaper type at well over 1,000 words a minute," or better than $12 \mathrm{msec} /$ letter.

The fact that this $10 \mathrm{msec} / \mathrm{character}$ rate seems to be independent of the spacing of the characters on the retina does not necessarily imply an immediate adjustment of the scan rate to character density. Evidence cited in the introduction suggests that information gained from a briefly presented display cannot be used to adjust processing strategies within that trial. It is more likely that subjects learn, during practice or training sessions, to preset their scan speed to the desired rate, and that this rate does not change within a trial.

The hypothesis that processing of successive array items overlaps in time can resolve an apparent conflict. The scanning data seem at odds with other data indicating that performance quickly falls to near-chance levels unless a minimum period of about 
40 msec elapses before the stimulus is "erased." When characters are presented sequentially, one at a time in the same location, processing rates come nowhere near $10 \mathrm{msec} / \mathrm{character}$. Mayzner, Tresselt, Checkes, and Hoenig (1970) published wholereport data for sequences of digits. With interstimulus intervals of 20,40 , and $60 \mathrm{msec}$, the first item in a twoitem sequence (where memory factors are unlikely to be involved) was reported correctly $58 \%, 72 \%$, and $86 \%$ of the time, respectively. The subjects of Sperling et al. (1971) attained their highest processing rates when successive frames of characters appeared every $\mathbf{4 0}$ to $50 \mathrm{msec}$; at shorter interstimulus intervals, their performance deteriorated. In this context, it is interesting to note that Donders $(1869 / 1969)$ found a period of approximately $\mathbf{4 0} \mathrm{msec}$ to be necessary for what he called "the development of a conception." He measured this by subtracting simple $\overline{R T}$ to a stimulus known in advance from simple $\overline{\mathrm{RT}}$ to the same stimulus when other stimuli could also appear. Recognition of the stimulus was necessary only in the second case.

We reconcile the $10-\mathrm{msec} /$ character scanning rate with what we call the "minimum encoding period" of $40 \mathrm{msec}$ by assuming that the scanning mechanism does not, in itself, do any processing. It merely fixes the time when processing of a given item begins. Processing of an item continues as subsequent items are scanned; eventually, several items are being processed at once. If we go on to postulate a capacity-limited system, in which the efficiency of processing a given item is inversely related to the number of items being processed simultaneously, we have a mechanism that can account for gap effects and U-shaped serial-position curves. The item that is scanned first has the advantage of no preceding items to compete with when it enters the processor. The item scanned last has a similar advantage, no competition from subsequently scanned characters. Items in the middle suffer most from overlapping, having to share processing capacity both with characters before them and characters after them. And this overlapping will be considerably reduced if some of these characters are removed, leaving a gap that the scanner must traverse.

This is a broad outline of the model that, in the following section, will be specified in precise detail. Many other models of overlapping processing are possible, just as there are many alternative models of serial processing and of parallel processing. The present example is designed primarily to deal with $\overline{\mathrm{RT}}$ data, although, with an additional assumption, it can be extended to accuracy data.

\section{A Model of Overlapping Processing}

Sternberg (1969) has defined four distinct processing stages between stimulus and response: stimulus encoding, serial comparison, binary decision, and response organization. We accept these four stages, but not Sternberg's assumption (p. 283) that "a stage should be able to process no more than one 'signal' at a time." We assume not only that several array items can undergo processing simultaneously, but in addition that the stages themselves overlap: one item may still be in Stage 1 while another has gone on to Stage 2. What maintains the statistical independence of the stages and enables us to generate additive (Donderian) predictions is the assumption that, for a given display item, processing is serial: for each item, one stage begins as soon as the preceding stage is completed.

A basic postulate of this model is that visual search is self-terminating. Once the display item that proves to be the target has been encoded and compared with the memory set, and a decision has been made, all processing of other items ceases. Thus, predicted RT for a given trial is the sum of the predicted processing times for the four stages, given a particular target position and display condition.

M. L. Shaw (1977) has shown that the linear relationship between $\overline{\mathrm{RT}}$ and the number of items in the memory set does not vary with serial position of the target. In a sequential visual search experiment, Hoffman (1978) has shown that this relationship is also independent of the rate at which characters are presented, provided that they are not superimposed. We therefore assume that Stage 2, comparison or testing, will not be affected either by serial position or by amount of overlap. Nor will these factors affect Stages 3 and 4 . This means that we can make predictions for each individual item in our arrays simply by adding a constant (for Stages 2,3 , and 4 ) to the predictions for the encoding stage.

We identify the encoding stage with that period of time during which the stimulus (or its trace) must be present, and assume a minimum encoding time of $\mathbf{4 0 ~ m s e c . ~ A n y ~ f a c t o r ~ t h a t ~ d e c r e a s e s ~ s t i m u l u s ~ l e g i - ~}$ bility, such as distance from the fovea, decay of the trace, lateral masking, dim illumination, and so on, will increase the amount of time it takes to encode that stimulus-which we call required encoding time, or $\tau$. The present model includes only two of these factors, retinal locus and decay. Characters scanned later have had a longer time to decay: in the case of a nine-item array, 80 msec elapse before processing begins on the last item. This period, which we call the prescan interval, is also considered as part of Stage 1. When there is a gap in the array the scanner neither speeds up nor slows down, so the prescan interval depends only on serial position.

Predicted encoding time, $T$, is determined not only by required encoding time, but also by the amount of competition or overlap. Overlap affects predicted encoding time by decreasing the rate or efficiency of encoding, $\xi$, where $0<\xi \leqslant 1$. $\xi$ is at its maximum, 1 , 
for an item that is alone in the encoder. If item $i$ must share processing capacity with other items, its rate of processing will depend on $m_{i}$, the number of items that were scanned before $i$ and are still being processed, and $n_{i}$, the number that are scanned after $i$ but before $i$ is completely processed. Thus, $\xi_{i}$ will change each time an item enters or leaves the encoder. The separate parameters for items before $i$ and items after i ("older" and "newer" items) permit the model to reflect the possibility that items may demand more (or less) processing capacity when they first enter than they do later on. The result is that each item in the encoder at a given point in time can have a different rate of processing.

Because of its pervasiveness in relationships between physical continua and their psychological correlates (Stevens, 1957), we have chosen the power function to represent the effects of $m$ and $n$ on rate of encoding. We adhere to the usual practice of assuming that the effects of decay of the trace and distance from the fovea proceed exponentially. Since our scanner moves at an invariant rate and display characters are evenly spaced, we can represent both of these stimulus degradation effects with a single exponential function.

If we call the moment when any item enters or leaves the encoder an event, we can define each interval of time between adjacent events as $t_{j}$. Then predicted encoding time for item $i$ is

$$
\mathrm{T}_{\mathrm{i}}=\sum_{\mathrm{j}=\mathrm{s}}^{\mathrm{w}} \mathrm{t}_{\mathrm{j}},
$$

where $t_{s}$ begins when item $i$ is scanned and the endpoint of the last interval, $t_{w}$, is reached whenever

$$
\sum_{j=s}^{w} t_{j} \xi_{i, j}=\tau_{i}
$$

The proportion $\xi_{i, j}$ denotes the efficiency of processing item $i$ during interval $t_{j}$.

$\xi_{i, j}$ is determined by $n$ and $m$ in the following relationship:

$$
\xi_{i, j}=\left[\lambda_{n}^{\log _{e}\left(n_{i, j}+1\right)}\right]\left[\lambda_{m}^{\log _{e}\left(m_{i, j}+1\right)}\right],
$$

where the parameters $\lambda_{\mathrm{n}}$ and $\lambda_{\mathrm{m}}$ are positive numbers between 0 and $1 .^{2}$ Note that if $n_{i}$ is zero (no items scanned after i), the function depends only on $m_{i}$, and vice versa.

Required encoding time for item $i, \tau_{i}$, depends on i's distance from the fixation point and decay of its trace. Both of these are determined by serial position. Using $i$ as an index of serial position gives us the following relationship:

$$
\tau_{i}=\left(\tau_{1}\right)\left(k^{i-1}\right) .
$$

The parameter $k(k \geqslant 1)$ controls the slope of this function. $\tau_{1}$ is required encoding time for the first display position. Since we assume that this position is located at the fixation point and is scanned at once, $\tau_{1}$ equals minimum encoding time, $40 \mathrm{msec}$.

Fitting to data. The predicted processing times for Stage 1, consisting of predicted encoding time plus the prescan interval, will be called the predicted $R T$ increment. We generated predicted RT increments for the seven combinations of target position and gap condition employed in Experiment 1; the $\overline{\mathrm{RT}}$ data from that experiment were used to estimate the three parameters, $\lambda_{n}, \lambda_{m}$, and $k$. The parameters were fit by a grid-search technique using a least-squares criterion. In order to make this fit, a constant of $385 \mathrm{msec}$ (representing Stages 2, 3, and 4) was added to each predicted RT increment, to bring it up to the level of the data. ${ }^{3}$ Means for all seven conditions, averaged over the four subjects, were fit simultaneously. The estimates for $\lambda_{n}, \lambda_{m}$, and $k$ were, respectively, .63, .84, and 1.14 .

Figure 2a shows the resulting RT increments predicted by the overlapping model for the three gap conditions used in our experiment. The $\overline{\mathrm{RT}}$ data from Experiment 1 are shown below, in Figure $2 b$. The model succeeded in providing a good fit to the data: it accounts for $87 \%$ of the variance in the data; ${ }^{4}$ the standard error of prediction is $14 \mathrm{msec}$. A number of characteristics of the data are predicted



Figure 2. Predicted and obtained RT as a function of target position and gap condition (before the target, after the target, control). (a) RT increment predicted by the overlapping model; (b) RT data from Experiment 1. 
by the model, including: (1) Gaps after the target in general produce a greater improvement than gaps before the target. (2) A gap before the target produces approximately the same change in RT for targets in position 5 and targets in position 7. (3) A gap after the target produces a greater change at position 7 , where the gap eliminates the last three items in the display, than at position 5 .

The model's predictions fail to agree with the data in one important way. The serial-position curve predicted by our model goes up almost linearly for the first few array items, then becomes negatively accelerated, and finally reverses direction at the end of the array. The serial-position curve obtained with our control displays and target positions 3, 5, and 7 is concave upward, or positively accelerated. M. L. Shaw (1977) measured RTs to targets in positions 1, 2, 4, and 6 in 10-item displays. She published serialposition curves for four individual subjects; three are concave upward. The discrepancy between these data and our model's prediction can perhaps be explained by the method used in these studies to control processing order. As a way of insuring that subjects began processing at position 1 , they were required to report the character in that position with almost perfect accuracy. This requirement may have caused them to increase their processing times for the first one or two display positions, causing $\overline{\mathrm{RT}} \mathrm{s}$ for items at the beginning of the display to be shifted upwards.

It should be pointed out that the validity of the overlapping model does not rest on the correctness of our a priori assumptions of a $10-\mathrm{msec} /$ character scanning rate and a 40-msec minimum encoding time. Had we, instead, allowed these attributes to vary as parameters, a closer fit to data could have been achieved, but at the cost of increasing the number of parameters from three to five.

\section{Predictions and Implications of the Overlapping Model}

The parameters $\lambda_{\mathrm{n}}=.63$ and $\lambda_{\mathrm{m}}=.84$ reflect the effects on processing efficiency of items that are scanned after $i$ and items that are scanned before $i$, respectively. Items following $i$ apparently have a more deleterious effect on the rate of processing $i$ than do items preceding it, although the difference is not great. The efficiencies generated by these parameters and Equation 3 are .73 and .89, respectively, for the older and newer of two items being processed at one time. When nine items are being processed at once-the maximum, with our parameters, since item 1 is finished before item 10 is scannedthe efficiency for each item from the oldest to the newest is $.36, .34, .34, .34, .36, .39, .43, .51$, and .68. The item that has been in the encoder the shortest time has the fastest rate of processing. This is in accord with Sperling's statement $(1970$, pp. 205206) "that information is acquired, at each letter position, most rapidly after the letter stimulus is turned on and that the rate diminishes as the exposure continues."

The effects of these efficiencies on predicted encoding time are graphically illustrated in Figure 3a. In this figure, the length of each bar represents encoding time for a single display item in a display containing 10 items and no gaps. The left end of each bar marks the time when the item in that serial position is scanned. This figure shows only the results of overlapping without the effects of retinal locus and decay of trace ( $k$ was set equal to 1.0). Note that predicted processing time increases with serial position and then declines again; encoding time for the last item is actually slightly less than for the first.

In Figure 3b, the effects of retinal locus and decay are added to those of overlapping by setting $k$
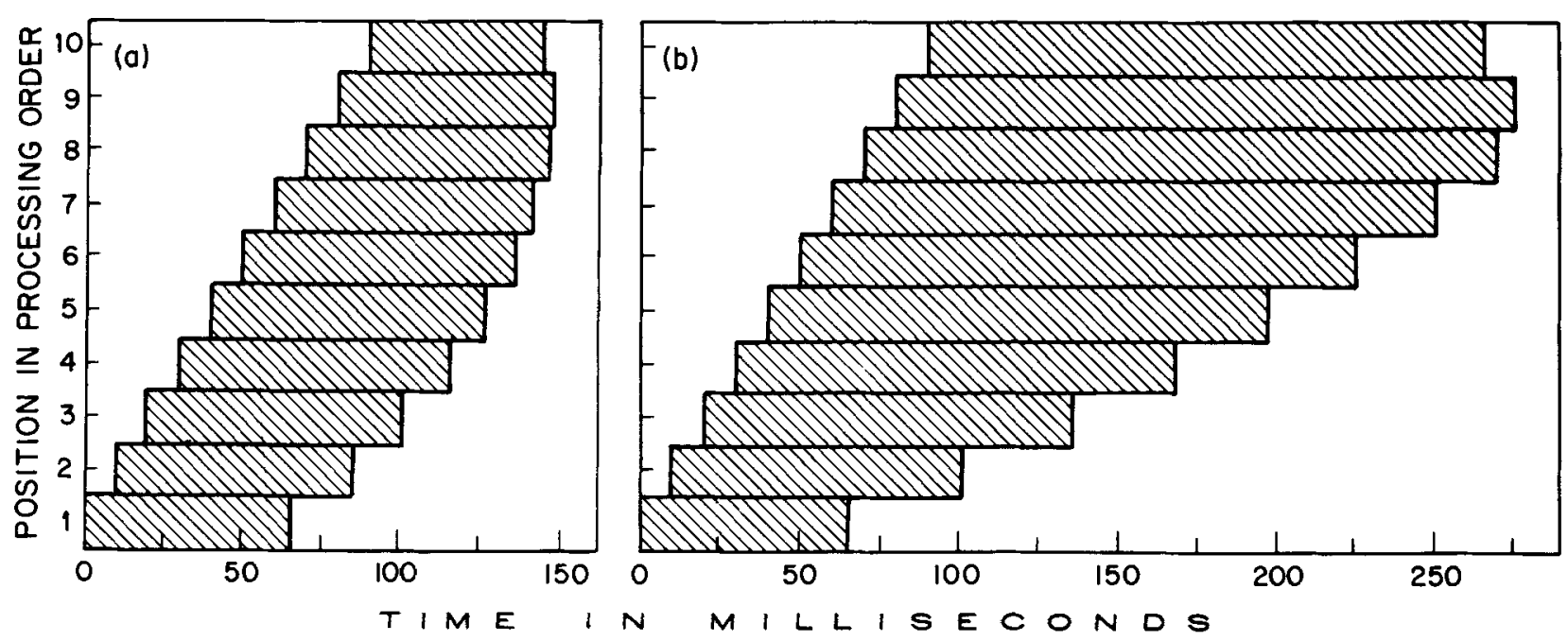

Figure 3. Encoding of overlapping items: (a) when $\tau_{i}$ (required encoding time) is 40 msec for every item; (b) when $\tau_{i}$ varies according to the formula $\tau_{i}=(40 \mathrm{msec})\left(1.14^{i-1}\right)$. The left end of each bar marks the time when that item is scanned, the right end the time when encoding of that item is completed. 
equal to 1.14 , as determined by our least-squares fit. The great increase in predicted encoding times (represented again by the length of the bars) is due not just to the increase in required encoding times $\left(\tau_{i}\right)$ but to the compounding of that increase by the effects of overlapping. Encoding time keeps increasing almost to the end of the array, then declines again for the last two items. Note that it is perfectly possible, with this model, for the processing of an item to be completed before that of an item that preceded it into the encoder: they need not come out in the same order they went in. In other words, this model predicts a shorter RT for the last item than for the next-to-last, a prediction in accord with whole-report accuracy data. A model with only a single parameter to represent the combined effects of $\mathrm{n}$ and $\mathrm{m}$ can produce only a monotonic curve of predicted RTs.

Testing. As each display item is encoded, it proceeds directly to the comparison or testing stage; processing overlaps in testing, too. Yet we assume that this overlap causes no decrease in processing efficiency. Does this mean the testing processor possesses unlimited capacity? More likely its capacity limitations have simply not been reached, because the encoding stage acts as a kind of bottleneck, slowing down the rate at which items enter the tester.

The basic characteristics of the testing stage postulated for the overlapping model are isomorphic with those of the self-terminating serial model for the case of single-item displays. But the two models generate different predictions for multicharacter arrays. M. L. Shaw (1977) pointed out that the serial self-terminating model predicts an interaction between serial position of the target and memory-set size: $\overline{\mathrm{RT}}$ should be a function of the total number of tests that must be performed, which should be target position times memory-set size. She found, instead, that $\bar{R} \mathrm{~T}$ increased linearly with memory-set size and that the slope of this increase remained remarkably invariant, regardless of the target's position in the display. In Figure 4, we show how the present model's combination of a capacity-limited encoding stage and an invariant testing stage can account for this result. In this figure, the lower, shaded area represents the same function shown in Figure $3 b$, but oriented so that the ordinate now measures units of time as in the usual RT graphs. The blocks on top each represent a comparison with a memory-set item; memory-set size in this example is three. As can be seen in Figure 4, changing the size of the memory set does not change the shape of the function relating predicted RT increment to display position. It simply raises it or lowers it by a constant amount.

A clue about the nature of testing is provided by data from markers. Our first experiment confirmed Holmgren's (1974) finding that when subjects did not know in advance whether a marker would be present, $\overline{\mathrm{RT}}$ was not improved by a marker located conspicuously over the target. But Holmgren showed that when it is expected to appear, the marker does speed up processing. Our interpretation is that testing of display items need not be confined to the form "Is it a B?" if a more effective test is available. However, the choice of which test or tests to perform must be made before the flash.

When it is known that a marker will appear over the target, display items can be tested with the question, "Does it have a marker?" Only the item that passes the marker test needs to be given a second test, "Is it a B?" Holmgren's data indicate that subjects can test for a marker more easily and quickly than for a letter, so that $\overline{\mathrm{RT}}$ can be improved with this pretest strategy. When subjects do not know for certain that a marker will be present, using this strategy would be counterproductive. Since a "no" outcome on the marker test would not prove that that character was a background item, the target

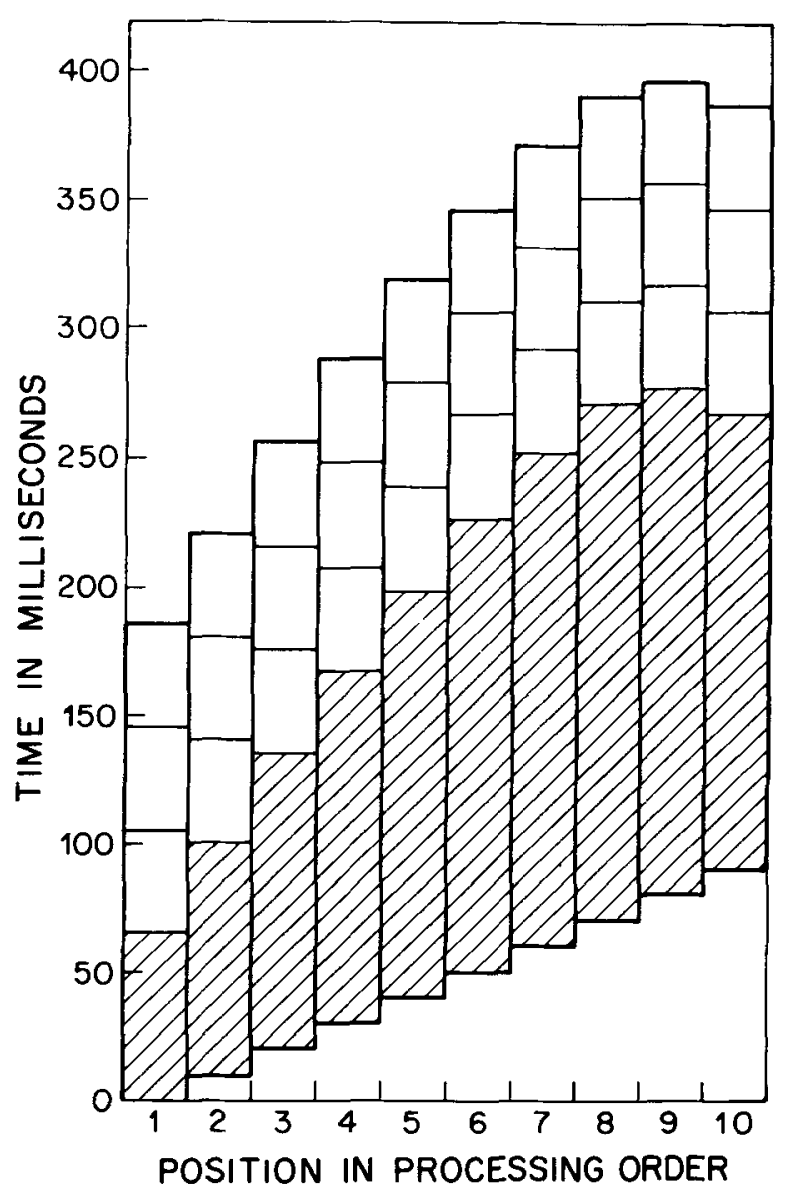

Figure 4. Encoding and testing of overlapping items. The bottom of each bar marks the time when that item is scanned, the shaded area is predicted encoding time, and each unshaded block is comparison with one memory-set item. 
could be missed entirely by relying on this test. Nevertheless, there is some evidence that subjects in our first experiment may have used this strategy occasionally. Although overall $\overline{\mathrm{RT}}$ did not differ significantly in marker and control trials, responses averaged $19 \mathrm{msec}$ faster on marker trials when the target was in position 7 , and $8 \mathrm{msec}$ slower when the target was in position 5. The marker pretest would save more time when the target was late in the processing order. For an early target there would be a slight disadvantage because of the second test that has to be performed. And if the trial proved not to contain a marker and the subject missed the target completely, it would be necessary to guess. Half of these guesses would be wrong; these responses would increase the error rate on nonmarker trials, accounting for the significant difference in accuracy found in Experiment 1.

Sequential presentations. What happens when items are presented one at a time, at a rate too fast to allow complete processing of each item before the next appears? As Sternberg and Scarborough's (1971) data indicated, processing overlaps. But the application of the overlapping model to sequential presentations is not as straightforward as it may seem.

The postulated effects of overlapping on processing speed have been confined to the encoding stage, and the encoding stage has been defined as the part of processing that requires the presence of the stimulus or its visual trace. When characters are presented one at a time in the same location, the trace of each item remains available only until the next item appears. Thus there is no overlapping of the encoding stage at all, and the model predicts a flat serial-position function! In line with this prediction, Sternberg and Scarborough reported no serialposition effects in their data.

We know of only one other visual search experiment that employed sequential presentations (Hoffman, 1978), but in this experiment the characters were not superimposed. The shortest interstimulus interval used in Hoffman's experiment was $25 \mathrm{msec}$. At this rate of presentation, there would never be more than two items being encoded at once, and the model predicts only a negligible change in RT with serial position. Hoffman states that no serial-position effect was detectable in his data.

U-shaped serial-position curves do, however, occur quite clearly in whole-report sequential data (Mayzner \& Greenberg, 1971; Mayzner et al., 1970). Part of this effect is no doubt attributable to memory processes. But we suspect than an equally important factor is the different kinds of processing required in visual search and whole-report tasks. The kind of testing required in visual search appears to demand so little processing capacity that no deficit due to overlapping occurs. But in the whole-report procedure the items must be identified. We propose that an additional processing stage-not requiring the presence of the stimulus trace-is necessary when an item must be named, and that this processing is subject to the effects of overiapping. The absence of this processing stage in visual search tasks can explain why background characters are not really "seen," in situations such as Neisser's (1964).

Masking. The present model accounts for most of the phenomena attributed to "lateral inhibition" or "masking" in terms of an overlapping system in which characters that are rapidly scanned in a given order compete for processing capacity. However, some kinds of masking effects seem not to depend on the speed or the order of processing, but to be more sensory in nature. We believe that these effects occur most noticeably when visual accuity is the limiting factor, as when characters are presented far from the fovea or are crowded closely together. For example, the displays of Estes et al. (1976) subtended $10.6^{\circ}$ of retinal angle; those of Townsend et al. (1971) subtended $3^{\circ} 5^{\prime \prime}$, but each of the nine characters was about $20^{\prime}$ wide. Although our model as presently quantified does not provide for effects of this nature, they can easily be added by assuming that they increase required encoding time.

The effects of array size. The relationship between RT and the number of items in the display has been the greatest source of difficulty for the serial selfterminating model. According to that model, the slope of the function for negative trials, when no target appears and every display item must be processed, should be double that for positive trials. This two-toone ratio for negative and positive slopes is occasionally obtained (Nickerson, 1966; Sternberg, Note 1). In other studies, the slopes are approximately equal (Atkinson et al., 1969; Townsend \& Roos, 1973), or the ratio of the slopes falls somewhere in between these two values (Holmgren, 1974). For the seven relevant studies reviewed by Gagnon, Cavanagh, and Laurencelle (1978), the mean ratio of negative to positive slope was 1.22 .

We generated predicted RT increments for arrays of different sizes, using the parameters derived from the fit to our data. We assumed exhaustive processing of display items on negative trials and self-terminating on positive, with random placement of the target. The resulting predictions for horizontal arrays of 1 to 10 items are shown in Figure 5.

Experiments in which array size is varied generally use arrays of one to five items. The results almost invariably fall on or near a straight line, and many theorists take a linear relationship between $\widetilde{R} \bar{T}$ and array size as one of the "givens." The array-size functions generated by the overlapping model are not linear; both positive and negative functions are concave upwards. But for the first five array sizes, 


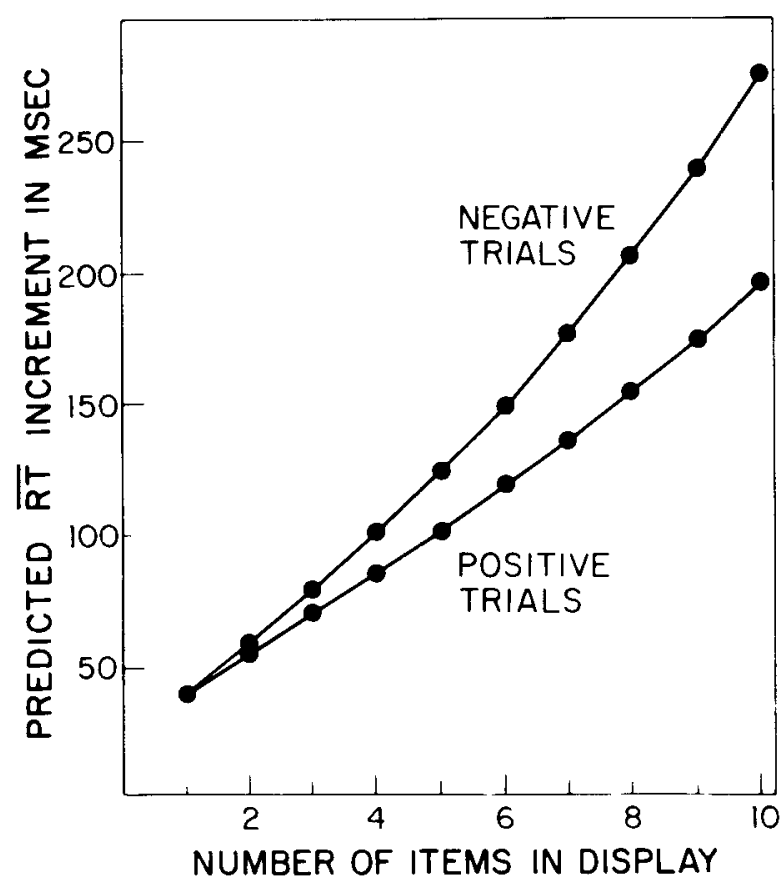

Figure 5. Predicted encoding time for positive and negative trials as a function of the number of items in a display. The display is assumed to consist of a continuous, evenly spaced string of characters, with the item processed first located closest to the fixation point.

these functions are so close to linear that no experimental test could detect the difference. Larger arrays must be used. In Holmgren's (1974) study, a definite upward curve is visible in the negative functions; in fact, the results deviated significantly from linearity for nonmarker trials. Holmgren varied array size from two to five, but added an "irrelevant" character on either side of the array. Thus, there were actually from four to seven characters in his displays.

For the first five array sizes, the slopes of the predicted negative and positive RT functions shown in Figure 5 are approximately 20 and $15 \mathrm{msec}$ per item, respectively-a ratio of 1.33 . Making a negative decision generally adds 50 or $60 \mathrm{msec}$ to total $\overline{\mathrm{RT}}$. Were we to add this decision time, the negative function would be displaced upwards by an amount considerably greater than the 20 -msec difference between positive and negative trials predicted for an array size of five.

Reported positive slopes for horizontal strings of characters have ranged from $11 \mathrm{msec} /$ item (Egeth, Atkinson, Gilmore, \& Marcus, 1973) to $66 \mathrm{msec}$ (Nickerson, 1966). The scanning rate postulated by our model sets $10 \mathrm{msec} /$ item as the theoretical lower limit for the array-size function (assuming that two items are never processed faster than one). However, this limit does not apply when "absent" items are replaced by noise characters (Schneider \& Shiffrin,
1977), or when items are placed around the perimeter of a circle of fixed diameter (Egeth et al., 1973; Egeth, Jonides, \& Wall, 1972). In these cases, every display location has to be scanned on every trial regardless of the number of items actually present, and the theoretical lower limit for the slope of the array size function becomes zero.

There is no theoretical upper limit on the slope of the array-size function. The functions shown in Figure 5 are based on the conditions of Experiment 1 . Less legible characters would increase minimum encoding time and perhaps slow the scanning speed; characters farther apart in visual angle would cause an increase in $\mathrm{k}$. Changes such as these would cause predicted RT increments to increase more rapidly with array size.

Since the array-size function is produced by a very different mechanism from the memory-set-size function, no particular relationship is expected between these two functions. Gagnon et al. (1978) found that, over a variety of experimental conditions, $\overline{\mathrm{RT}}$ increased more rapidly with memory-set size than with array size. They concluded that different processes are responsible for the two functions, a conclusion consistent with the model presented here.

The overlapping model predicts that $\overline{\mathrm{RT}}$ to a target in the position processed first will increase with array size, until an asymptote is reached. There is some support for this prediction in the reports of Atkinson et al. (1969) and Townsend and Roos (1973). In both studies, $\overline{\mathrm{RT}}$ to a target in the leftmost position appeared to increase with array size. Unfortunately, these data are subject to other interpretations, since Atkinson et al. did not control processing order, and in both studies the arrays were centered, so that the leftmost item was farther from the fixation point in the larger arrays.

Predictions of accuracy results. The assumptions made in quantifying the overlapping model were designed for a situation in which RT is measured and the probability of a correct response is very high. Can this model be modified to suit a different situation, in which accuracy is measured and the probability of a correct response varies over a wide range?

In order to lower accuracy into the desired range of variation, experimenters make the job of detecting or identifying characters difficult. The exposure time may be short, the number of characters large, or the stimuli dim or distorted. The result is that there is not enough time to encode each character completely. Although each item is only partially encoded, enough information about its characteristics is gained so that the probability of a correct identification is above zero.

Quantification of the overlapping model based predictions of encoding time, $T_{i}$, on the assumption that encoding was completed. These predicted encod- 
ing times were a function of retinal locus and decay (as determined by serial position and $\mathrm{k}$ ) and of the amount of overlap (determined by $n, m, \lambda_{n}$, and $\lambda_{m}$ ). If only a certain, fixed amount of time, $A$, is actually allotted to encoding item $i$, then each item will receive only the proportion $A / T_{i}$ of the amount of encoding needed to encode it completely. In Figure 6a, we have plotted $A / T_{i}$ as a function of serial position for each item in a display of nine, again using the parameters derived from Experiment 1 to estimate $T_{i}$, and setting $A$ equal to the $T_{i}$ for position 1 , $66 \mathrm{msec}$. (Since accuracy is generally perfect for the position processed first, we assume that item 1 is completely encoded.) In Figure 6b, we have plotted the whole-report data from Estes and Wolford (1971), using only the two conditions in which instructed processing order started with the item closest to the fixation point. The two functions correspond closely in shape; however, performance falls off more rapidly than $A / T_{i}$ : items that presumably received $40 \%$ of the encoding time needed for near-perfect performance were reported correctly less than $10 \%$ of the time. The probable source of this difference is that when subjects are asked to report nine items

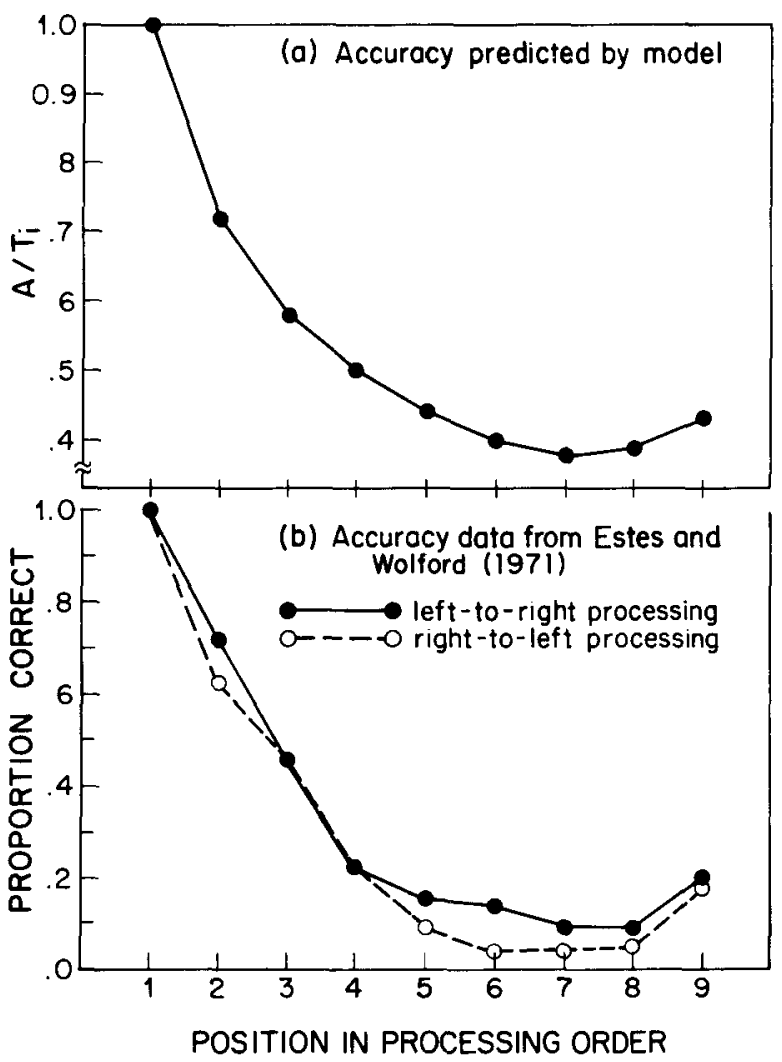

Figure 6. Predicted and obtained accuracy performance for a nine-item array as a function of processing order. (a) Allotted processing time (66 msec) divided by predicted processing time for item i. (b) Data from Estes and Wolford (1971) for two directions of processing; in both conditions, item 1 was the closest to the fixation point.
Table 4

Obtained and Predicted Accuracy Measurements

\begin{tabular}{cccc}
\hline $\begin{array}{c}\text { Display } \\
\text { Condition }\end{array}$ & $\begin{array}{c}\text { Target } \\
\text { Position }\end{array}$ & $\begin{array}{c}\text { Fxperiment 2 } \\
\text { Accuracy* }\end{array}$ & $\begin{array}{c}\text { Predicted } \\
\text { Accuracy** }\end{array}$ \\
\hline Gap Before & 5 & .82 & .81 \\
Target & 7 & .63 & .65 \\
Gap After & 5 & .93 & .95 \\
Target & 7 & .86 & .91 \\
No Gap & 3 & .95 & .90 \\
(Control) & 5 & .77 & .66 \\
*Proportions correct, mean of three subjects. & $* * 104 \mathrm{msec} / T_{i}$.
\end{tabular}

at once, they are not likely to remember those items about which they have the least information.

The same method for extending the overlapping model to the prediction of accuracy performance was applied to the visual search data from Experiment 2, with promising results. The values used for $\lambda_{n}$, $\lambda_{\mathrm{m}}$, and $\mathrm{k}$ were again those derived from Experiment 1. A (actual encoding time allotted per item) was obtained from a least-squares fit to the Experiment 2 data, because using $66 \mathrm{msec}$, the predicted (complete) encoding time for item 1, underestimated performance. We found that setting $A$ equal to $104 \mathrm{msec}$, so that each item was assigned $104 \mathrm{msec} /$ $T_{i}$ of the time it needed to be completely encoded, produced predictions that accounted for $84 \%$ of the variance in the Experiment 2 data; the standard error of prediction was .053 . Table 4 shows the predicted and obtained values. Since the subjects in this experiment had to make only one response, memory factors were not involved.

If accuracy is a function of the proportion of the full encoding time that is actually allotted to encoding, we can interpret speed-accuracy tradeoff functions (Pachella, 1974) as the results of varying that proportion. However, since an extreme emphasis on accuracy is likely to result in a slowing down of all processing stages, the shape of the speed-accuracy function cannot be attributed solely to the length of the encoding period.

\section{Conclusions}

We have postulated a simple, efficient system for visual search, consisting chiefly of three parts: a scanner that cannot vary its speed within a trial, an encoder that can process a number of items at once though not as fast as it can process one, and a tester that proceeds at an invariant rate regardless of how many items it is processing. Complete encoding of an item will take more or less time depending on retinal locus, decay of the visual trace, and how many other items overlap with it in the encoder; if encoding is incomplete, accuracy will suffer. Gap effects and serial-position curves are explained by the assumption that the rate of encoding an item is affected by the number of characters 
scanned before it and the number of characters scanned after it; these two effects are quantitatively different, though qualitatively the same.

Visual search is assumed to be self-terminating: it ceases once processing of the target is completed. But because of overlapping, when the number of items in the display is within the usual range, processing all of them (on negative trials) takes only a little longer than processing some of them (on positive trials). This model generates array-size functions for RT that are concave upward; with arrays of five items or less, however, the functions for positive and negative trials are nearly linear and not very different in slope. Memory-set-size functions are assumed to be linear, and to arise from an independent source.

The $10-\mathrm{msec} / \mathrm{character}$ scan rate postulated here determines how much overlapping of processing will occur. In different situations, this scan rate may vary, and hence the degree of overlap. If we picture degree of overlap as a continuum, then the two extremes of this continuum will be no overlap (i.e., serial) and complete overlap (parallel). Thus serial and parallel processing can be considered special cases of overlapping.

Perhaps the greatest advantage of the overlapping model is that it posits a method of processing that can be applied to sequentially presented arrays as well as to those presented all at once, and to short, briefly presented arrays as well as to the lengthy strings of characters and gaps that constitute printed text.

\section{REFERENCE NOTE}

1. Sternberg, S. Scanning a persisting visual image versus a memorized list. Paper presented at the meeting of the Eastern Psychological Association, Boston, April 1967.

\section{REFERENCES}

Atrinson, R. C., Holmgren, J. E., \& Juola, J. F. Processing time as influenced by the number of elements in a visual display. Perception \& Psychophysics, 1969, 6, 321-326.

BAXT, N. Über die Zeit welche nötig ist, damit ein Gesichtseindruck zum Bewusstsein kommt und über die Grösse (Extension) der bewussten Wahrnehmung bei einem Gesichtseindrucke von gegebener Dauer. Pflüger's Archiv für die Gesamte Physiologie, 1871, 4, 325-336.

Donders, F. C. Over de snelheid van psychische processen. Onderzoekingen gedaan in het Physiologisch Laboratorium der Utrechtsche Hoogesehool, 1868-1869, Tweede reeks, II, 92-120. Translated by W. G. Koster in W. G. Koster (Ed.), Attention and performance II. Amsterdam: North-Holland, 1969. (Reprinted from Acta Psychologica, 1969, 30).

Egeth, H., Atrinson, J., Gilmore, G., \& Marcus, N. Factors affecting processing mode in visual search. Perception \& Psychophysics, 1973, 13, 394-402.

Egeth, H., Jonides, J., \& Wall, S. Parallel processing of multielement displays. Cognitive Psychology, 1972, 3, 674-698.

Eriksen, C. W., \& Hoffman, J. E. Some characteristics of selective attention in visual perception determined by vocal reaction time. Perception \& Psychophysics, 1972, 11, 169-171.

Estes, W. K. Interactions of signal and background variables in visual processing. Perception \& Psychophysics, 1972, 12, 278-286.

Estes, W. K., Allmeyer, D. H., \& Reder, S. M. Serial position functions for letter identifications at brief and extended exposure durations. Perception \& Psychophysics, 1976, 19, 1-15.

Estes, W. K., \& Wolford, G. L. Effects of spaces on report from tachistoscopically presented letter strings. Psychonomic Science, 1971, 25, 77-80.

Gagnon, M., Cavanagh, P., \& Laurencelle, L. Processing differences between memory search and foveal visual search. Perception \& Psychophysics, 1978, 23, 258-260.

GARDNER, G. T. Evidence for independent parallel channels in tachistoscopic perception. Cognitive Psychology, 1973, 4, 130-155.

Hoffman, J. E. Search through a sequentially presented visual display. Perception \& Psychophysics, 1978, 23, 1-11.

Holmgren, J. E. The effect of a visual indicator on rate of visual search: Evidence for processing control. Perception \& Psychophysics, 1974, 15, 544-550.

KINCHLA, R. A. The role of structural redundancy in the perception of visual targets. Perception \& Psychophysics, 1977, 22, 19-30.

Koopman, B. O. The theory of search; Part III: The optimum distribution of searching effort. Operations Research, 1957, $5,613-626$.

Krueger, L. E. Evidence for directional scanning with the orderof-report factor excluded. Canadian Journal of Psychology, 1976, 30, 9-14.

Krumhansl, C. L., \& Thomas, E. A. C. Extracting identity and location information from briefly presented letter arrays. Perception \& Psychophysics, 1976, 20, 243-258.

MAyzNeR, M. S., \& GReEnberg, J. Studies in the processing of sequentially presented inputs with overprinting paradigms. Psychonomic Monograph Supplements, 1971, 4(4, Whole No. 52).

Mayzner, M. S., Tresselt, M. E., Checkes, J., \& Hoenig, H. A. Visual information processing of sequentially presented inputs: III. Further effects of list length and interstimulus interval values on subspan storage and retrieval mechanisms. Perception \& Psychophysics, 1970, 7, 294-296.

Neisser, U. Visual search. Scientific American, 1964, 210(6), 94-102.

Neisser, U., Novick, R., \& Lazar, R. Searching for ten targets simultaneously. Perceptual \& Motor Skills, 1963, 17, 955-961.

Nickerson, R. S. Response times with a memory-dependent decision task. Journal of Experimental Psychology, 1966, 72, 761-769.

Pachella, R. G. The interpretation of reaction time in information-processing research. In B. H. Kantowitz (Ed.), Human information processing. Tutorials in performance and cognition. Hillsdale, N.J: Erlbaum, 1974.

Rumelhart, D. E. A multicomponent theory of the perception of briefly exposed visual arrays. Journal of Mathematical Psychology, 1970, 7, 191-218.

Schneider, W., \& Shiffrin, R. M. Controlled and automatic human information processing: I. Detection, search, and attention. Psychological Review, 1977, 84, 1-66.

Shaw, M. L. Reaction time in reading a tachistoscopic display for a memory set item. Perception \& Psychophysics, 1977, 21, 15-25.

SHAw, M. L. A capacity allocation model for reaction time. Journal of Experimental Psychology: Human Perception and Performance, 1978, 4, 586-598.

Shaw, M. L., \& Shaw, P. Optimal allocation of cognitive resources to spatial locations. Journal of Experimental Psychology: Human Perception and Performance, 1977, 3, 201-211.

Shaw, P. Processing of tachistoscopic displays with controlled order of characters and spaces. Perception \& Psychophysics, $1969,6,257-266$.

SPE rling, G. The information available in brief visual presentations. Psychological Monographs, 1960, 74(11, Whole No. 498). 
Sperling, G. A model for visual memory tasks. Human Factors, $1963,5,19-31$.

Spe Rling, G. Short-term memory, long-term memory, and scanning in the processing of visual information. In F. A. Young \& D. B. Lindsley (Eds.), Early experience and visual information processing in perceptual and reading disorders. Washington, D.C: National Academy of Sciences, 1970.

Sperling, G., Budiansky, J., Spivak, J. G., \& Johnson, M. C. Extremely rapid visual search: The maximum rate of scanning letters for the presence of a numeral. Science, 1971, 174, 307-311.

STERnBERG, S. The discovery of processing stages: Extensions of Donders' method. In W. G. Koster (Ed.), Attention and performance II. Amsterdam: North-Holland, 1969. (Reprinted from Acta Psychologica, 1969, 30.)

Sternberg, S., \& Scarborough, D. L. Parallel testing of stimuli in visual search. In Proceedings of the International Symposium on Visual Information Processing and Control of Motor Activity. Sofia: Bulgarian Academy of Sciences, 1971.

Stevens, S. S. On the psychophysical law. Psychological Review, 1957, 64, 153-181.

TAYLOR, D. A. Stage analysis of reaction time. Psychological Bulletin, 1976, 83, 161-191.

Townsend, J. T. Issues and models concerning the processing of a finite number of inputs. In B. A. Kantowitz (Ed.), Human information processing: Tutorials in performance and cognition. Hilisdale, N.J: Erlbaum, 1974.

Townsend, J. T., \& Roos, R. N. Search reaction time for single targets in multiletter stimuli with brief visual displays. Memory \& Cognition, 1973, 1, 319-332.

Townsend, J. T., TAylor, S. G., \& Brown, D. R. Lateral masking for letters with unlimited viewing time. Perception \& Psychophysics, 1971, 10, 375-378.

UEno, T. Temporal summation in human vision: Simple reaction time measurements. Perception \& Psychophysics, 1978, 23, 43-50.
Wolford, G. L., \& Hollingsworth, S. Lateral masking in visual information processing. Perception \& Psychophysics, 1974, 16, 315-320.

\section{NOTES}

1. Although P. Shaw's (1969) model was based on the assumption that a gap before the target did not improve performance, a closer look at his four relevant experiments reveals that this condition produced significant improvement in 4 out of 21 possible comparisons with control. None of these 21 intrasubject comparisons significantly favored the control condition. Considering only the direction of differences, $P$. Shaw's experiments seem to fall into two categories: in the last three experiments, 10 out of 12 comparisons favor the gap-before-target condition; in the first experiment, 8 out of 9 favor the control. There is no obvious explanation for this discrepancy.

2. In the alternative formula, $\xi_{i, j}=\left(n_{i, j}+1\right)^{\alpha}\left(m_{i, j}+1\right)^{\beta}$, the parameters $\alpha$ and $\beta$ are negative exponents. We have found Equation 3 to be a more convenient way of expressing this function.

3. We account for the $385 \mathrm{msec}$ of nonencoding time as follows: Approximately $210 \mathrm{msec}$ are required for simple RT (Ueno, 1978), where the subject just sees a light (no encoding assumed to be necessary) and pushes a button (no motor decision necessary). Subtracting this time leaves $175 \mathrm{msec}$. If tests against the memory set take $\mathbf{4 0} \mathrm{msec}$ each, then $80 \mathrm{msec}$ is required for Stage 2 testing in our experiments. The remaining $95 \mathrm{msec}$ is divided between a Stage 3 decision, that a tested item was the target, and a Stage 4 decision, which button to push.

4. The formula for the proportion of variance accounted for is given by M. L. Shaw (1977).

(Received for publication July 5, 1978; revision accepted May 3, 1979.) 